\title{
Attitudes and Self-Efficacy of Arabic-speaking Physical Education Teachers in Israel toward Including Children with Disabilities
}

\author{
Yeshayahu Hutzler ${ }^{1,2}$, Einas Daniel-Shama ${ }^{3}$ \\ ${ }^{1}$ The Academic College at Wingate, Wingate Institute Israel, Israel \\ ${ }^{2}$ Israel Sport Center for the Disabled, Israel \\ ${ }^{3}$ University of Tiraspol, Moldova \\ Correspondence: Yeshayahu Hutzler, The Academic College at Wingate, Wingate Institute Israel, Israel.
}

Received: August 23, 2017

Accepted: September 15,2017 Available online: September 25, 2017

doi:10.11114/ijsss.v5i10.2668

URL: https://doi.org/10.11114/ijsss.v5i10.2668

\begin{abstract}
The purpose of this study was to explore the attitudes and self-efficacy (SE) of physical education (PE) teachers in the Arabic-speaking educational sector in Israel toward including children with disability in their classes, utilizing translated questionnaires. The specific goals were (a) to describe the structure and internal consistency of the responses to the Attitudes Toward Inclusion in Physical Education (ATIPE) and Situation Specific Self-Efficacy (SE-ASPE) questionnaires of an Arabic-speaking PE teachers' sample, (b) to assess the effect of selected background variables on attitudes and SE in the study population, (c) to determine the association between SE and attitudes toward including children with disabilities in PE in the study population, and (d) to describe the differences in PE teachers' SE toward including children with different disabilities. The results indicated a bi-dimensional factor structure of the ATIPE and an unidimensional structure of each of the SE-ASPE subscales: intellectual disability (ID), physical disability (PD), and visual impairment (VI), and confirmed an internal reliability. The impact of background variables on attitudes and SE indicated that females had more favorable attitudes and SE than males, age had a small significant impact, training, and experience in inclusion of children with disability had a significant impact. Finally, it was found that the SE toward including children with VI was lower than toward ID and PD. Based on our findings it can be recommended that the training processes be strengthened, and include continuous education workshops on inclusion with an emphasis on VI.
\end{abstract}

Keywords: special needs, education, integration; intervention, participation, teacher preparation

\section{Introduction}

The inclusion pedagogy, where children with disabilities are supported within regular classes is understood as a framework to providing rich learning opportunities that are sufficiently made available for everyone, enabling all learners to participate in classroom life, has become a favorable practice in recent years (Florian \& Black-Hawkins, 2011). According to the inclusion educational philosophy, it is believed that providing adaptations and supports for children with disabilities within a regular educational setting in their community is the major practical basis for inclusion of students with disabilities in the regular school system, thus enabling their holistic development and enhancing their opportunities to achieve normative educational goals (Barton, 1993). Inclusion principles have been acknowledged in the United Nation Convention on Rights of Persons with Disability (United Nations, 2006), and their implementation has been studied within adapted physical education (APE) research in the USA since the 1980s (e.g., Rizzo, 1984), in Europe since the 1990s (e.g., Lienert, Sherrill, \& Myers, 2001; Meegean, \& MacPhail, 2006; Schmidt-Gotz, Doll-Tepper, \& Lienert, 1994), and more recently in South America (Columna et al., 2016) and Asia (e.g., Qi, Wang, \& Ha, 2016). Israel began to implement supportive systems in a variety of frameworks, including the school system where supportive legislation had already been accepted a decade earlier with the seventh amendment (Article Four) of the Special Education Law, known as Integration Law (Worgen, 2007). In Israel, physical education (PE) is provided to students in all schools twice a week for 45 minutes each session. However, in a nationwide survey among 363 Israeli PE teachers regarding their perception of burnout (Fejgin, Talmor, \& Erlich, 2005), the authors found that more than half of the teachers reported that children with sensory or motor impairments were not at all or only partially included in the school's PE classes.

In contrast to the western individual growth and self-determination perspective (Polloway, Smith, Patton, \& Smith, 
1996), which appears to be present in the Jewish majority in Israel (Florian, Weisel, Kravetz, \& Shurka-Zernitsky, 1989), Islamic cultures encourage practicing a merciful approach toward people disability, providing them with various measures of relief due to their reduced capacities. Due to this incongruence between western and Islamic perspective a gap can be observed in understanding between clients and providers, potentially leading to poor treatment or rehabilitative outcomes (Hasnein, Shaikh, \& Shanawani, 2008).

Attitude research is one of the most common methods of social research to identify barriers for the inclusion of minorities, such as persons with disabilities (Chubon, 1982). Attitudes are described as human beliefs towards others or towards social phenomena (Triandis 1971) constructed of beliefs, feelings, and actions (Ajzen, 1991; Antonak \& Li nneh, 1988). From a social cognitive point of view, attitude - like other human functioning - can be understood as the result of the interaction between personal, environmental, and task- or activity-specific factors, in which all contribute to the resulting behavior (Wood \& Bandura, 1989). Within this interaction, self-efficacy (SE) is viewed as both a context- and a task-specific belief in the capability of an individual to master a task to a certain degree; it is one of the most important moderators of attitude and intention toward a desired behavior, and is a determining factor for achievement behaviors (Bandura, 1993; 1997; 2005). SE has been preferred over theories, which are limited mainly to prediction (Bandura, 1997), such as the theory of Planned Behavior, and has been recommended as a theoretical framework for studying the beliefs of prospective PE teachers toward inclusion (Block, Taliaferro, Harris, \& Krause, 2010; Taliaferro, Hammmond, \& Wyant, 2015).

Research on PE teacher attitudes towards including children with disabilities in physical education has been extensively studied and a complete description of this frame of reference can be found elsewhere (e.g., Block \& Obrusnikova, 2007; Hutzler, 2003; Taliaferro et al., 2015). SE has become a focus of research in this population only in the last two decades (e.g., Block, Hutzler, Klavina, \& Barak, 2013; Hutzler, Zach, \& Gafni, 2005). Briefly, research has acknowledged several determinants of PE teachers' attitudes and SE, including (a) length of teaching experience; (b) amount of time acquainted with persons with disability (c) training and experience in teaching children with disabilities within inclusive settings, and (d) gender.

The intercultural gap between Muslim and Western society, reported by Hasnein and associates (2008), may have an impact on the attitudes of PE teachers in an Arabic population and also may restrict the acquisition of an inclusive perspective, which could adversely influence PE teachers' attitudes and SE toward including children with disabilities in their classes. When the Islamic cultural perspective of applying a merciful approach toward persons with disability is contrasted with the PE teachers' desire to enhance physical capacity and performance, and to present challenges, the teachers may develop negative attitudes toward the inclusion of children with lower physical capabilities in their classes. Furthermore, marginalization in many Middle Eastern and African countries toward children with disabilities (see Peters, 2009) may also negatively impact the perspectives on including children with disability in Arab populations. Indeed, studies in Middle East countries (Alsalhe, 2013), and Iran in particular (Shahi \& Jadidi, 2013), revealed reluctance and hesitation on the part of PE teachers toward including students with disability in their classes. Such cultural perspectives may have been transferred into the cultural framework of teachers in the Arabic-speaking educational sector in Israel, and could potentially influence their perspective on including children with disabilities.

Therefore, we were interested in exploring the attitudes and SE of Arabic-speaking PE teachers in Israel toward including children with disability in their classes. This study had several purposes: (a) to describe the structure and internal consistency of attitudes and SE questionnaires in the teachers' sample, (b) to assess the effect of selected background variables on attitudes and SE in the study population, (c) to determine the association between SE and attitudes toward including children with disabilities in PE in the study population, and (d) to describe the differences in PE teachers' SE toward including children with different disabilities.

\section{Method}

\subsection{Participants}

The study sample was concentrated in one Arabic-speaking district with 26 schools. Out of 175 teachers registered in this education district, located around the city of Nazareth,,160 (68 females and 92 males) responded to our sample (92\%). The non-respondents were teachers on maternity leave, were ill, or were not willing to fill in the consent form. The schools in which these teachers taught include both governmental and private schools, and had a population of junior (elementary) school, middle school, and high school students. Teaching experience was classified based on five-year increments of experience. As such, participants comprised a complete group rather than a sample, representing the total Arab PE teachers' population in the particular area of Nazareth and surroundings, with about 70\% Moslems which is quite similar to the national distribution (Central Bureau of Statistics, 2016; Chmaissi, 2003). The group comprises a mixture of urban and rural populations living in municipalities of the fourth and fifth socio-economical deciles, which is typical for the Arab population in Israel (Central Bureau of Statistics, 2006). 


\subsection{Instruments}

Three questionnaires were used in this study. The first was a demographic questionnaire similar to the one utilized by Taliaferro and her associates (2015). The attitude questionnaire was developed in Israel for assessing attitudes of PETE students toward inclusion (Hutzler et al., 2005). The third was a situation- and disability-specific instrument developed in the USA for a similar population. All three questionnaires were translated from Hebrew or English to Arabic by three professionals with a Master's degree who taught Hebrew, Arabic, or English. The translated questionnaires were back-translated, and consensus was applied for refining the final versions (Brislin, 1970). A detailed description of each questionnaire follows. 2.2.1. Demographic Background Questionnaire.

Four background variables were examined: (a) participation or non-participation in an academic course addressing inclusion; (b) previous experience or lack of previous experience with children with disability; (c) the teacher's gender; and (d) number of years of experience in teaching. Closed-ended questions were used to explore variables a-c. For exploring variable $\mathrm{d}-$ the number of years of experience, an open-ended question was used. However, the total years' range of experience was collapsed into five five-year periods (i.e., 0-5; 6-10;11-15;16-20; 21 years or more). In variable $b$, when participants answered that they had participated in specific training, the number of courses was also requested to be reported. The teachers' demographic background variables are reported in Table 1.

Table 1. Participants' background variables

\begin{tabular}{cc}
\hline Variable & Outcomes \\
\hline Gender & Males $=92 ;$ Females $=68$ \\
Age & Mean $=34 ;$ SD $=8.7$ years \\
Teaching experience (N) & $0-5=57 ; 6-10=25 ; 11-15=36 ; 16-20=22 ;>20=20$ \\
Grade level & Junior school $=35 ;$ Junior \& high school $=135$ \\
APE Training & $=<2$ course $=84 ;=>3$ courses $=76$ \\
Experience ID & Yes $=60 ;$ No \\
Experience PD & Yes $=55 ;$ No=105 \\
Experience VI & Yes=75; No=85 \\
\hline
\end{tabular}

Note: $\mathrm{APE}=$ Adapted physical education; $\mathrm{ID}=$ Intellectual disability; $\mathrm{PD}=$ Physical disability; $\mathrm{VI}=$ Visual impairment.

\subsubsection{Attitude Questionnaire toward Inclusion in PE (ATIPE)}

This scale deals with the perception of the difficulties and the advantages of integrating children with disabilities/abnormalities in physical education, adapted by Hutzler and associates (2005) from the original scale of Shechtman (1991), which was de veloped for teachers who do not specialize in PE. The resulting questionnaire contains 15 short statements referring to beliefs concerning the context of inclusion. All statements are phrased in a positive format and expanded from a dichotomous scale ("yes" and "no") into a four-point scale (Range $1=$ Not at all agree, $2=$ To some extent agree, 3 = Mostly agree, 4 = Absolutely agree), in order to reduce the risk of social desirability bias. Additional adjustments to the original scale were made to for compliance with the PE framework. The adjustments were examined and confirmed by a team of five experts in teacher education and special education, and further established with a factor analytical procedure performed on the ATIPE (Hutzler et al., 2005). This proce dure generated three factors, demonstrating Cronbach alpha coefficients ranging from .71 - .87, which can be described as good internal consistency (Cohen, 1988). Two of the factors, "Threat to the teacher" and "Threat to the class" were in the opposite direction of the third factor - Opportunities ( $r=-.41$ and -.34 respectively). The ATIPE scale was translated into Serbian and utilized for measuring attitudes of 84 primary school teachers (Đorđić, Tubić, \& Protić, 2014).

\subsubsection{Situation-Specific Self-Efficacy toward Inclusion Scale for PE Teacher Education majors (SE-PETE-D) (Block et} al., 2013)

This survey was designed to study the perceptions of SE of PE teachers or students towards the inclusion of students with disabilities into the PE programs in schools. Based on previous attitude surveys in Europe and the USA (e.g., Downs \& Williams, 1994; Hodge \& Jansma, 1999), it was concluded that different disabilities are differentially perceived by practitioners, and that intellectual or physical disability (ID or PD, respectively) and visual impairment (VI) were recognized as demonstrating the major challenge to PE teachers (Block et al., 2013; Lieberman, Robinson, \& Rollheiser, 2006; Rizzo \& Vispoel 1991; Sideridis \& Chandler, 1996). This survey examines the PE teacher's or student's confidence in his or her ability to include a child, using three subscales that measure participant's SE perceptions toward each of the three disabilities addressed. This instrument has been developed with regard to Bandura's (2006) recommendations for constructing SE instruments, however with an adapted five-point scale. In addition, validation was performed to measure PETE majors' self-efficacy toward including students with ID, PD, and VI in PE frameworks, including teaching skills, playing sport games, and performing fitness activities. The SE-PETE-D was found to present two to three factors within each of the subscales, demonstrating acceptable to good internal consistency (Block et al., 2013). 
Responses in each of the disability subscales were analyzed separately, using a scale of 1 (no confidence) to 5 (complete confidence) in each item. The introduction and structure of each of the subscales within the SE-PETE-D instrument are similar. Each subscale is preceded by a vignette demonstrating a student with an ID, PD, or VI who would be attending a general PE class. An example of the vignettes follows, in accordance with Block and associates (2013, pp.188-189).

Three sets of questions (varying across disability categories) followed the vignette, focusing on the degree of confidence the respondent felt in any of the specific contexts of conducting fitness testing (3-4 questions), teaching sport skills (3-5 questions), and organizing the actual playing of a sport (3-4 questions). In total, there were 10-12 questions for each disability subscale. Examples of typical questions in each context can be found in the validation study of Block and associates (2013). In order to specify the subscales of ID, PD, and VI in the translated scale the subscales will be designated hereafter with the prefix SE-ASPE (Self-efficacy of Arab speaking physical educators), followed by PD, \& VI suffices, rather than using the SE-PETE-D prefix.

\subsection{Procedure}

Prior to performing the study, permission from the chief scientist of the Ministry of Education was received, as well as from the Ethics Review Board of the Faculty and each of the participating schools. The second author individually addressed all the teachers in person, by phone or mail, based on data provided by the department of education in the local authority to which the schools belong. All participants signed an informed consent and filled in the questionnaires in the same order, as follows: The ATIPE first, followed by the SE-ASPE-ID, PD, and VI, and finally, the demographic questionnaire. Questionnaires were returned to the investigator in person or via mail. They were then transformed into a data sheet and statistically processed.

\subsection{Data Analysis}

\subsubsection{Exploratory Factor Analysis (EFA)}

The EFA employed in this study to reveal the structure and reliability of the three subscales of the SE-ASPE and the ATIPE included a principal component analysis (PCA) extraction method, followed by orthogonal (varimax) rotation to maximize variance. Statistical assumptions necessary for establishing a scale's structure (Field, 2005) were tested. The Kaiser-Meyer-Olkin (KMO) index of sampling adequacy had to be higher than 0.75 , and the Bartlett's test of sphericity had to be highly significant ( $\mathrm{p}<0.001$ ) (Tabachnick \& Fidell, 2001). While generating factors, three variables were the minimum per factor for ensuring stability (Costello \& Osborne, 2005). A communality of less than 0.40 caused a factor to be removed from the analysis (Velicer \& Fava, 1998) and necessitated the PCA to be repeated. "Crossloading" of items was defined when an item loaded at 0.32 or higher on two or more factors (Costello \& Osborne, 2005). Such items were dropped from the analysis and the PCA was repeated. Following the PCA, a Cronbach alpha reliability analysis was conducted in each factor and in the complete scale. A minimum of alpha $=0.70$ was set for adequate reliability (Tabachnick \& Fidell, 2001).

\subsubsection{The Influence of Participants' Background Factors}

The impact of age was assessed using correlation analysis. The effect of teaching experience was assessed using a general linear model comparing experience periods that generally ranged five years each (i.e., $0-5 ; 6-10 ; 11-15 ; 20-25$; 26 and more years). These periods were entered into a one-way ANOVA with scale score as the dependent variable. Tukey post-hoc analyses revealed differences between periods. Additional background factors, including gender, participation in an academic course (one or less compared to two or more courses), and previous acquaintance with children with disabilities (yes or no) were considered as a dichotomy, and analyzed using t-tests. Effect-sizes supported the inference statistics with partial Eta ${ }^{2}$ and Cohen's $d$ scores computed for the ANOVA and t-tests, respectively.

\subsubsection{Additional Procedures}

The association between the SE-ASPE-subscales and the ATIPE were measured via correlation analysis. One-way ANOVAs were computed to reveal differences across disability groups in each questionnaire. All procedures were conducted with IBM SPSS 15 software (IBM Corporation, NY, USA).

\section{Results}

\subsection{Questionnaire Structure and Reliability}

Before conducting the PCA, we tested the statistical indices for assuming [assessing?] the structural validity and reliability of the attitudes and SE questionnaires. The KMO index for the ATIPE was 0.937 and for the SE-PETE-D 0.957; 0.956; and 0.987 for the ID; PD and VI subscales respectively. Barlett's test of sphericity $\mathrm{Chi}^{2}$ was statistically significant in the ATIPE and in the three SE-ASPE ID, PD, and VI subscales. Based on these results, we assumed that the sample size was adequate and the extracted factors accounted for substantial variance.

For the ATIPE, a two-factor solution was computed, together explaining $82.9 \%$ of the variance. The subscale "Threats" 
with 11 items explained $72.4 \%$ of the variance; $a=.97$, and the "Opportunities" subscale with four items explained an additional $10.5 \%$ of the variance; $\mathrm{a}=.875$.

Each of the disability subscales of the SE-ASPE was separately analyzed. All subscales presented a single factor solution. The factor solution for the ID subscale explained $85 \%$ of variance; $a=.97$; the PD subscale explained $87 \%$ of variance; $a=.96$; and the VI subscale explained $90 \%$ of variance; $a=.97$.

These indices satisfy the homogeneity and reliability of the scales used in the current survey.

\subsection{Participants'Background Factors}

\subsubsection{Age}

The effect of age across the questionnaire subscales was assessed using Pearson correlations. Most correlations were trivial, and only the SE-ASPE-ID subscale presented a small positive correlation $(\mathrm{r}=.33 ; p<.01)$. The details of the relationships can be found in Table 2 .

Table 2. Relationships between Subscales and participants' age

\begin{tabular}{ccc}
\hline Instrument & $\mathbf{R}$ & $\boldsymbol{P}$ \\
\hline ATIPE Threat & 0.22 & $<.01$ \\
ATIPE Opp. & 0.16 & $<.05$ \\
SE-ASPE - ID & 0.33 & $<.01$ \\
SE-ASPE -PD & 0.28 & $<.01$ \\
SE-ASPE - VI & 0.12 & NS \\
\hline
\end{tabular}

Note: SE-ASPE $=$ Self-efficacy of Arabic-speaking physical educators; Opp.= Opportunities subscale; ID = Intellectual disability; $\mathrm{PD}=$ Physical disability; $\mathrm{VI}=$ Visual impairment.

\subsubsection{Gender}

T-tests computed between males and females present significant differences ( $p$ range <.005 - .001) in all subscales of both questionnaires. Female teachers had more favorable results than male teachers. Table 3 presents additional details of outcomes in each of the subscales surveyed, representing mostly moderate effect sizes. In the SE-ASPE-VI subscale the difference between females and males reached a large effect size.

Table 3. Means and standard deviations (SD) of questionnaire scores across gender

\begin{tabular}{|c|c|c|c|c|c|c|c|}
\hline \multirow[t]{2}{*}{ Instrument } & \multicolumn{2}{|c|}{ Mean } & \multirow[t]{2}{*}{$\mathbf{t}$} & \multirow[t]{2}{*}{$\boldsymbol{P}$} & \multicolumn{3}{|c|}{ Confidence interval } \\
\hline & Males & Females & & & Upper & Lower & $d$ \\
\hline ATIPE threat & $2.00(1.05)$ & $1.36(0.47)$ & -4.62 & $<.001$ & 0.36 & 0.9 & 0.79 \\
\hline ATIPE Opp. & $2.771 .01)$ & $3.22(0.71)$ & -3.1 & $<.002$ & -0.72 & -0.16 & -0.52 \\
\hline SE-ASPE- ID & $2.95(1.27)$ & $3.61(0.71)$ & -3.76 & $<.001$ & -0.99 & -0.31 & -0.64 \\
\hline SE-ASPE-PD & $2.92(1.32)$ & $3.71(0.7)$ & -448 & $<.001$ & -1.14 & -0.44 & -0.75 \\
\hline SE-ASPE- VI & $2.37(1.22)$ & $3.31(0.91)$ & -5.28 & $<.001$ & -1.28 & -0.58 & -0.87 \\
\hline
\end{tabular}

Note: SE-ASPE = Self-efficacy of Arabic-speaking physical educators; Opp.= Opportunities subscale; ID = Intellectual disability; $\mathrm{PD}=$ Physical disability; $\mathrm{VI}=$ Visual impairment.

\subsubsection{Years of Teaching Experience}

Findings of the one-way ANOVA with Tukey post-hoc analyses revealed significant main effects as well as post-hoc effects $(p<.05)$ in both ATIPE subscales between teachers with only one to five years of experience compared to those with more years of experience $\left(\mathrm{F}[159,4]=6.92 p<.0001\right.$; partial Eta ${ }^{2}=0.151$ for the Threats; and $\mathrm{F}[159,4]=6.04 ; p<.0001$; partial $\mathrm{Eta}^{2}=0.135$ for the Opportunities subscales). The details of these findings can be seen in Figure 1. Teachers with zero to five years of experience exhibited significantly greater Threats and lower Opportunities than those with six years or more. Figure 1: Attitudes of participants with different teaching experience toward students with different disabilities.

Note: * Denotes that the group of participants with $0-5$ years (Yrs) of experience were significantly different than all the other experience ranges. F4,155= 10.6 in ID ( $\mathrm{p}<.0001) ; 12.1$ in PD ( $\mathrm{p}<.0001)$; and 3.81 in VI ( $<<.005)$.

Figure 2 depicts the SE-ASPE subscale scores in participating teachers across their years of experience. Significant one-way ANOVAeffects revealed that scores were greater in PE teachers with experience longer than five years for the ID, $\mathrm{PD}$, and VI subscales $\left(\mathrm{F}[159,4]=10.58 p<.0001 ;\right.$ partial $\mathrm{Eta}^{2}=0.214 ; \mathrm{F}[159,4]=12.1 ; p<.0001 ;$ partial $\mathrm{Eta}^{2}=0.238$; and $\mathrm{F}[159,4]=3.81 p<.005$; partial $\mathrm{Eta}^{2}=0.09$ respectively). Post hoc analyses revealed that in the ID subscale differences were observed between teachers with $0-5$ years of experience and all other teachers. In the PD subscale differences were observed between teachers with 0-5 years and those with 6-15 years, while in the VI subscale a significant difference was only presented between teachers with 0-5 and 11-15 years of experience. The more experienced teachers exhibited greater SE than the novice teachers. 


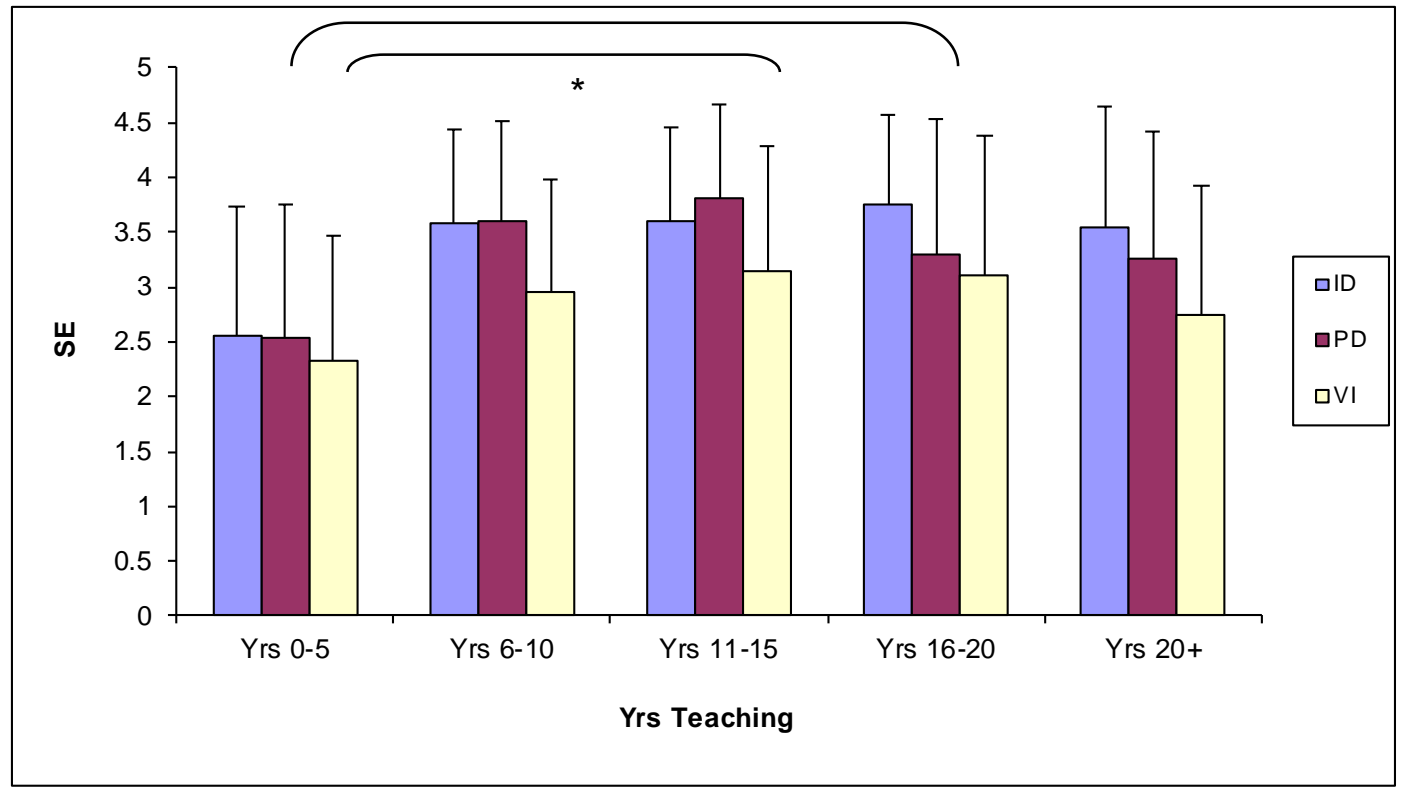

Figure 2. Self-efficacy (SE) of Arabic-speaking physical educators (SE-ASPE) of participants with different teaching experience toward students with different disabilities

Note: $\neg$ denote the groups significantly different from 0-5 years of experience (Yrs) for ID and PD; * denotes the group different from Yrs 0-5 for VI. ID = Intellectual disability; PD = Physical disability; VI = Visual impairment.

\subsubsection{Participation in an Academic Adapted Physical Education (APE) Course}

Teacher responses regarding their volume of participation in adapted physical activity training were divided between those attending two courses or less and those attending three courses or more during their basic or continuing education programs. Results of the t-test and Cohen's $d$ effect sizes across the volume of participation are presented in Table 4 . Teachers who had attended three courses or more had significantly more favorable scores with large effect sizes on all measures than those who had less academic training toward inclusion.

Table 4. Means, standard de viations (SD) and t-test results of questionnaire scores across teachers attending training courses in integrating students with disability

\begin{tabular}{|c|c|c|c|c|c|c|c|}
\hline Instrument & $\begin{array}{l}\text { hours } \\
\text { (SD) } \\
=<1 \text { hour }\end{array}$ & $\begin{array}{l}\text { Training } \\
\text { Mean } \\
=>2 \text { hours }\end{array}$ & $t$ & $p$ & $\begin{array}{l}\text { Confidence } \\
\text { Lower }\end{array}$ & $\begin{array}{c}\text { Interval } \\
\text { Upper }\end{array}$ & $\begin{array}{c}\text { Cohen's } \\
\text { d }\end{array}$ \\
\hline ATIPE threat & 2.13 (1.02) & $1.28(0.47)$ & 6.61 & $<.001$ & 0.59 & 1.1 & 1.07 \\
\hline ATIPE Opp. & $2.54(0.93)$ & $3.43(0.64)$ & -6.93 & $<.002$ & -1.14 & -0.63 & -1.11 \\
\hline SE-ASPE- ID & $2.65(1.06)$ & $3.9(0.78)$ & -8.44 & $<.001$ & -1.54 & -0.96 & -1.34 \\
\hline SE-ASPE- PD & 2.65 (1.09) & $3.95(0.80)$ & -8.53 & $<.001$ & -1.61 & -1.00 & -1.36 \\
\hline SE-ASPE- VI & $2.27(1.05)$ & $3.32(1.09)$ & -6.14 & $<.001$ & -1.38 & -0.71 & -0.98 \\
\hline
\end{tabular}

Note: SE-ASPE $=$ Self-efficacy of Arabic-speaking physical educators; Opp.= Opportunities subscale; ID = Intellectual disability; $\mathrm{PD}=$ Physical disability; $\mathrm{VI}=$ Visual impairment. .

\subsubsection{Experience in Including Students with Disabilities}

The effect of having experience in providing PE to students with disabilities was assessed using t-tests between those who indicated that they had experience and those who did not. The experience was related to each of the three types of disability assessed within the SE-ASPE subscales. The outcomes are presented in Tables 5-7. Each of these tables represents questionnaire scores referring to having or not having experience in including students with ID, PD, and VI, respectively. Most results indicated significant differences with large Cohen's $d$ effect sizes in favor of those who had experience. The type of disability in which the experience was gained did not have a major impact.

In total, 100 participants reported they had an experience in integrating students with ID, 105 in integrating students with 
PD, and 85 in integrating students with VI. Participants who had experience demonstrated significantly more favorable scores than those who had no experience in including children with disability, regardless the type of disability in which they had an experience. One exception was participants who had experience in including children with ID. These participants did not reveal significant differences regarding their SE in including students with PD.

Table 5. Means, standard deviations (SD) and t-test results of questionnaire scores across teachers having experience in including students with ID

\begin{tabular}{|c|c|c|c|c|c|c|c|}
\hline \multirow[t]{2}{*}{ Instrument } & \multirow{2}{*}{$\begin{array}{c}\text { Mean } \\
\text { No experience }\end{array}$} & \multirow{2}{*}{$\begin{array}{c}(\mathbf{S D}) \\
\text { With experience }\end{array}$} & \multirow[t]{2}{*}{$\mathbf{t}$} & \multirow[t]{2}{*}{$p$} & \multicolumn{2}{|c|}{ Confidence interval } & \multirow[t]{2}{*}{$\begin{array}{c}\text { Cohen's } \\
d\end{array}$} \\
\hline & & & & & Upper & Lower & \\
\hline ATIPE Threat & $2.381 .06)$ & $1.34(0.51)$ & 8.36 & $<.0001$ & -0.79 & 1.28 & 1.13 \\
\hline ATIPE Opp. & $2.31(0.93)$ & $3.35(0.66)$ & -8.28 & $<.0001$ & -1.29 & -0.79 & -1.29 \\
\hline SE-ASPE - ID & $2.35(1.02)$ & $3.78(0.80)$ & -9.81 & $<.001$ & -1.71 & -1.38 & -1.56 \\
\hline SE-ASPE - PD & $2.34(1.01)$ & $3.82(0.86)$ & -9.78 & $<.005$ & -1.77 & -1.17 & -1.58 \\
\hline SE-ASPE - VI & $2.01(0.94)$ & $3.231 .09)$ & -7.21 & NS & -1.55 & -0.88 & -1.20 \\
\hline
\end{tabular}

Note: SE-ASPE = Self-efficacy of Arabic-speaking physical educators; Opp.= Opportunities subscale; ID = Intellectual disability; $\mathrm{PD}=$ Physical disability; $\mathrm{VI}=$ Visual impairment .

Table 6. Means, standard deviations (SD) and t-test results of questionnaire scores across teachers having experience in including students with PD

\begin{tabular}{|c|c|c|c|c|c|c|c|}
\hline \multirow[t]{2}{*}{ Instrument } & \multirow{2}{*}{$\begin{array}{c}\text { Mean } \\
\text { No experience }\end{array}$} & \multirow{2}{*}{$\begin{array}{c}\text { (SD) } \\
\text { With experience }\end{array}$} & \multirow[t]{2}{*}{$\mathbf{t}$} & \multirow[t]{2}{*}{$p$} & \multicolumn{2}{|c|}{ Confidence interval } & \multirow[t]{2}{*}{$\begin{array}{c}\text { Cohen's } \\
d\end{array}$} \\
\hline & & & & & Upper & Lower & \\
\hline ATIPE Threat & $2.381 .06)$ & $1.34(0.51)$ & 8.36 & $<.0001$ & -0.79 & 1.28 & 1.13 \\
\hline ATIPE Opp. & $2.31(0.93)$ & $3.35(0.66)$ & -8.28 & $<.0001$ & -1.29 & -0.79 & -1.29 \\
\hline SE-ASPE - ID & $2.35(1.02)$ & $3.78(0.80)$ & -9.81 & $<.001$ & -1.71 & -1.38 & -1.56 \\
\hline SE-ASPE - PD & $2.34(1.01)$ & $3.82(0.86)$ & -9.78 & $<.005$ & -1.77 & -1.17 & -1.58 \\
\hline SE-ASPE - VI & $2.01(0.94)$ & $3.231 .09)$ & -7.21 & NS & -1.55 & -0.88 & -1.20 \\
\hline
\end{tabular}

Note: SE-ASPE = Self-efficacy of Arabic-speaking physical educators; Opp.= Opportunities subscale; ID = Intellectual disability; $\mathrm{PD}=$ Physical disability; $\mathrm{VI}=$ Visual impairment.

Table 7. Means, standard deviations (SD) and t-test results of questionnaire scores across teachers having experience in including students with VI

\begin{tabular}{|c|c|c|c|c|c|c|c|}
\hline \multirow[t]{2}{*}{ Ins trument } & \multirow{2}{*}{$\begin{array}{c}\text { Mean } \\
\text { No experience }\end{array}$} & \multirow{2}{*}{$\begin{array}{c}\text { (SD) } \\
\text { With experience }\end{array}$} & \multirow[t]{2}{*}{$\mathbf{t}$} & \multirow[t]{2}{*}{$\boldsymbol{P}$} & \multicolumn{2}{|c|}{ Confidence interval } & \multirow[t]{2}{*}{$\begin{array}{c}\text { Cohen's } \\
d\end{array}$} \\
\hline & & & & & Upper & Lower & \\
\hline ATIPE Threat & $2.201 .03)$ & $1.31(0.52)$ & 6.97 & $<.0001$ & -0.63 & 1.34 & 1.09 \\
\hline ATIPE Opp. & $2.50(0.93)$ & $3.34(0.73)$ & -6.16 & $<.0001$ & -1.07 & -0.55 & -1.00 \\
\hline SE-ASPE- ID & $2.59(1.03)$ & $3.81(0.87)$ & -8.15 & $<.0001$ & -1.52 & -0.93 & -1.28 \\
\hline SE-ASPE - PD & $2.60(1.11)$ & $3.85(0.82)$ & -8.02 & $<.0001$ & -1.56 & -0.94 & -1.28 \\
\hline SE-ASPE - VI & $1.94(0.83)$ & $3.500 .95)$ & -11.03 & $<.0001$ & -1.85 & -1.29 & -1.75 \\
\hline
\end{tabular}

Note: SE-ASPE = Self-efficacy of Arabic-speaking physical educators; Opp.= Opportunities subscale; ID = Intellectual disability; $\mathrm{PD}=$ Physical disability; $\mathrm{VI}=$ Visual impairment.

\subsubsection{Association between Attitudes and SE}

The association between the attitude and SE instruments across each of the five subscales is demonstrated in Table 8 . The Pearson's correlations between the SE subscales were significant and ranged between $.805-.924(p<.001)$, which is considered large (Cohen, 1988). The correlations between all SE-ASPE subscales and the ATIPE Threats subscale were significant and negative (range -.653 to $-.795 ; p<.001$ ), indicating moderate to large associations. The correlations between all SE-ASPE subscales and the ATIPE Opportunities subscale were significant (range .594 to.75; $p<.001$ ), also indicating moderate to large associations. The correlation between both ATIPE subscales was significant, negative, and large $(\mathrm{r}=.886, p<.001)$.

Table 8 . Association between the study instruments across subscales

\begin{tabular}{lcccc}
\hline & SE-ASPE- PD & SE-ASPE - VI & Attitude - Threat & Attitude - Opp. \\
\hline SE-ASPE - ID & 0.924 & 0.805 & -0.795 & 0.746 \\
SE-ASPE - PD & & 0.829 & -0.808 & 0.75 \\
SE-ASPE - VI & & & -0.653 & 0.594 \\
Attitude Threat & & & & -0.886 \\
\hline
\end{tabular}

Note: All Correlations were significant $(p<.001)$. SE-ASPE $=$ Self-efficacy of Arabic-speaking physical educators; Opp.= Opportunities subscale; ID = Intellectual disability; PD = Physical disability; VI = Visual impairment. 


\subsubsection{Impact of Disability}

While the ATIPE questionnaire is disability non-specific, the SE-ASPE includes three different subscales, each of which demonstrates a unique and challenging disability condition. A one-way ANOVA within subjects across disability subscales was employed in order to address the differences in survey participants' SE when challenged with including children with different disabilities. Due to the significant differences found between males and females, gender was considered a moderating variable.

In the SE-ASPE the findings exhibited significant effects for Disability $\left(\mathrm{F}[155,2]=58.6 ; p<.001 ;\right.$ Partial $\left.^{2 t a}{ }^{2}=0.271\right)$, and for the interaction of Disability * Gender $\left(\mathrm{F}[155,2]=3.86 ; p<.05 ;\right.$ Partial $\left.\mathrm{Eta}^{2}=0.024\right)$. Post-hoc pair-wise comparisons depicted that the SE expressed for including students with VI was significantly lower than for including students with ID or PD. This trend was more significant in the female participants. Figure 3 illustrates the details of this finding.

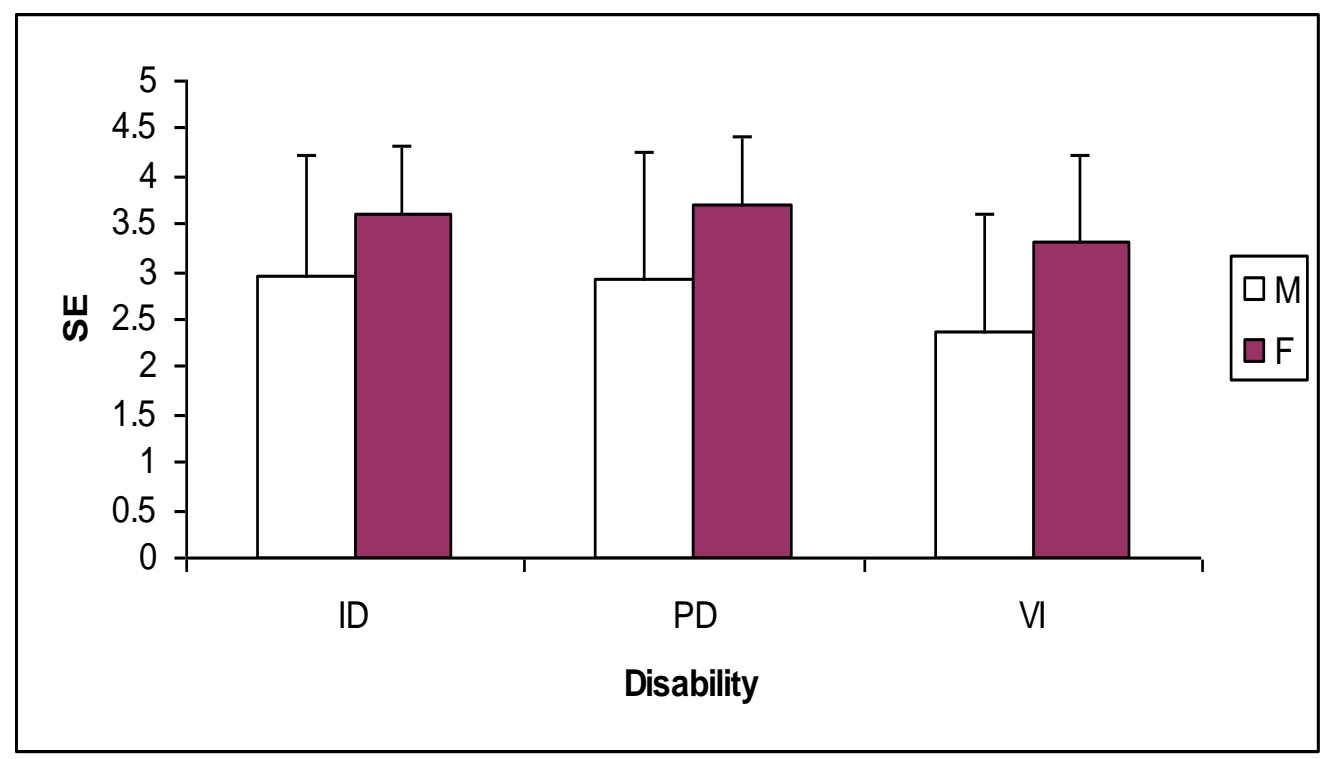

Figure 3. Self-efficacy (SE) of Arabic-speaking physical educators (SE-ASPE) of males and females across different disability groups

Note: * denotes that PE Teachers' SE-ASPE in the VI subscale was significantly different than the two other subscales $(p<.05)$. This difference was stronger in the males. $\mathrm{M}=$ Males; $\mathrm{F}=\mathrm{Females}$.

\section{Discussion}

The purposes of this study were (1) to explore the attitudes and SE of Arabic-speaking PE teachers in Israel toward integrating students with several disabilities in their PE classes, and (2) to determine the effects of age, gender, teaching experience, course work in APE, and having specific experience in teaching students with disabilities, on the attitudes of the specific ethnical and cultural group of Arabic-speaking PE teachers in Israel toward inclusion of children with ID, PD, and VI. In addition, we wanted to examine the relationship between the perception of SE in participants to include students with disabilities and their attitudes towards these students.

\subsection{Attitudes and Self-Efficacy Scales' Structure}

While the original ATIPE scale (Hutzler et al., 2005) demonstrated three subscales (threat to teacher, threat to class, and opportunities), the two-threat subscales merged into a single-threat scale in the ATIPE instrument, which was [OK?] translated into Arabic. Furthermore, in contrast to the three or two factors in each of the SE-PETE-D subscales that were exposed in the original study (Block et al. 2013), only one factor was obtained in the SE-ASPE utilized in the current study. The original factor structure of the ATIPE (Hutzler et al., 2005) was similar to the Czech scale labeled Attitudes towards Teaching Indi viduals with Physical Disabilities in Physical Education - ATIPDPE (Kudlaček, Valkova, Sherrill, Myers, \& French, 2002), which originally demonstrated three factors: positive outcomes for students, negative outcomes for students, and negative outcomes for teachers. However, in the Greek validation study (Doulkeridou, Evaggelinou, \& Kudláček, 2010), similar to the current study, a two-factor solution was obtained where the two negative outcomes factors - one for students and one for the teachers - merged into one factor, while in the Slovenian validation study the original three-factor solution remained (Kudláček, Blanková, \& Filipčič, 2007). As for the SE-ASPE structure in the current sample, a one-factor solution for each subscale was also reported in the study of Taliaferro et al. (2015), in contrast to the two to three factors obtained in the original study (Block et al. 2013). However, 
in a recent Czech validation study with PE majors, the original factor structure of two factors in the ID, three factors in the PD, and two factors in the VI subscales has remained (Baloun, Kudlacek, Sklenarikova, Jesina, \& Migdauova, 2016). An additional recent study, performed with a translated version of the SE-PETE-D in Valencia, Spain (Reina, Hemmelmayer, \& Sierra-Marroquin, 2016), did not include a factor analysis.

The results for Cronbach's reliability analysis of the SE-ASPE reached very high scores ( $\alpha$ for the ID subscale $=0.96, \alpha$ for the PD subscale $=0.97, \alpha$ for the VI subscale $=0.98$ ) and were comparable Cronbach's $\alpha$ values obtained in previous surveys conducted in the USA, ranging 0.86 - 0.96 (Block et al. 2013; Taliaferro et al. 2015), and to those reported by Reina et al. (2016) in a fairly similar sample of 102 practicipng teachers (59.8\% males) with a mean experience of $14.87 \pm 9.02$ years ( $\alpha=0.975$ for the PD subscale and 0.935 for both the ID and VI subscales). These outcomes appear to present a similar hrather than a different response pattern of the Arabic-speaking PE teachers to American and European samples.

\subsection{Attitudes and Self-Efficacy Scores}

Although the movement toward "inclusive education" is anchored in the broad human rights agenda in international conventions and national legislation, many educators still have serious reservations about supporting the widespread placement of students with disabilities in mainstream schools (Block and Obrusnikova 2007). Based on a North American perspective, Obrusnikova (2008) concluded that the beliefs of PE teachers toward teaching children with disabilities were generally positive, but that they varied according to the type of disability. Beliefs were reported to be more favorable toward teaching children with specific learning disabilities and less favorable toward teaching children with emotional and behavioral disorders. In our study we found a generalized attitude toward including children with various disabilities, which was measured by means of ATIPE, and specific SE perceptions toward including children with either ID, PD or VI by means of SE-ASPE. Mean ATIPE scores for both males and females were slightly above the average in the opportunities subscale and below the average in the threat subscale. Slightly above average scores were also reported in several previous studies - for example, in practicing PE teachers in four out of five Spanish-speaking South and Central American countries (Columna et al., 2016), in both general and adapted prospective PE teachers in the Czech Republic (Kudlaček et al., 2002), and in Australian preservice PE teachers' intentions toward including students with ADHD or autism (Pedersen, Cooley, \& Hernandez, 2014). SE scores as measured with the SE-ASPE instrument were also mostly above average, except for male scores in the VI subscale. Above average values were also obtained in the preservice teacher sample of Block et al. 2013, and in an in-service PE teacher sample even prior to practicum intervention (Taliaferro et al., 2015). As has been indicated, PE teachers' attitudes and SE toward including children with disability is influenced by a multitude of individual background factors. In the following sections the specific impact of each factor will be discussed. Therefore, in addition to the fairly similar pattern, the magnitude of outcomes in the Arabic-speaking PE teachers from the northern region of Israel also seem to be similar to that of American and European teachers.

\subsubsection{Age}

The significant low relationship found between age and attitude or SE in our study seems to be in accordance with previous studies from the USA, which did not indicate an impact of teachers' age on their attitudes toward inclusion (e.g., Rizzo \& Vispoel, 1991; Rizzo \& Wright, 1988; Tripp \& Rizzo, 2006). However, in a few studies conducted about a decade after a policy change towards inclusion in the respective countries - (Rizzo, 1984) in the USA and Özer and associates (2013) in Turkey, younger teachers seemed to benefit more than older ones from the normative and curricular changes associated with the legislative reform. Therefore, it may be suggested that in the current study no impact of an inclusive reform was demonstrated. Indeed, very limited expectations have been expressed in Israel regarding inclusion in PE. Furthermore, no forms of support are regularly provided for PE teachers to engage in the inclusion of students with disability in their class.

\subsubsection{Gender}

Females had significantly more favorable attitudes and SE toward inclusion than male teachers in the current study. Previous research findings on PE teachers' attitudes, present inconsistent results, with the majority of studies indicating no gender difference (Hodge, Davis, Woodward, \& Sherrill, 2002; Kudlaček et al., 2002; Özer et al,. 2013; Patrick, 1987; Rizzo, 1984; Rizzo \& Vispoel, 1991; Rizzo \& Wright, 1988; Rowe \& Stutts 1987). However, similar to the current study, a previous study conducted in Israel with PETE students (Hutzler et al. 2005) and a few studies conducted in Germany (Schmidt-Gotz et al., 1994) and in the USA (Aloia, Knutson, Minner, \& Von Seggern, 1980) also indicated more favorable attitudes of females.

Based on the Theory of Reasoned Action, the significant differences found in both attitude and SE regarding all disability groups in favor of the females may suggest that females have acquired the norm of teaching under diverse conditions, incorporated in the inclusion approach (Ajzen, 1991), while the male teachers appear to still conform to the 
norm of accomplishing the designated task such as teaching the class a specfic skill, for which a child with disabilities who requires extra attention may produce a threat. Another explanation of this gender difference may be the different attributes of each gender. Numerous findings in the USA reported by Bain (1990) suggest that males are more conservati ve and authoritarian, and have a strong orientation towards coaching rather than teaching (Aloia et al., 1980). The stronger authoritarian and coaching orientation may increase their role conflict when facing the need to include a child with disability, and thus may produce a greater perceived threat among male teachers. PE teacher educators should be aware of this tendency and provide a range of collaborative and empowering education practices that support a more student-centered rather than normative and authoritarian teacher orientation, particularly in the males students.

\subsubsection{Teaching Experience}

In the current study teachers with experience of 6-20 years had more favorable attitudes and SE towards inclusion than those with experience of only 0 to 5 years; Regarding inclusion of students with visual impairment, this trend was only significantly demonstrated in teachers with experience of 11 to 20 years. Our findings are in contrast to the findings of Özer et al. (2013) in Turkey, who revealed that in a representative sample the PE teacher with more experience possessed less favorable attitudes toward inclusion than did their younger counterparts, thus consistent with earlier research which suggested that younger and less experienced teachers tend to be more receptive regarding the idea of including students with disabilities (Rizzo \& Vispoel, 1991; Rizzo \& Wright, 1988). The main reason for this difference was believed to be due to the introduction of the new Physical Education Teaching Program in 2000 involving all Turkish universities. Initially APE took place in Turkey as an obligatory PE teaching curriculum for one semester in 2000, and subsequently a "Special Education" course and an APE practical course were added in 2005. Younger teachers who were educated in universities during the past 12 years have received various degrees of training in APE, thus strengthening the teachers' knowledge base about how to include children with disabilities.

The difference in results obtained between our study and the American and Turkish studies may be explained by the differing legislative frameworks, and the different PE teacher education programs resulting from the legislative reform. In contrast to Turkey, where inclusion has been practiced only in the last decade and thus not permitting enough exposure and experiences within the PE practice, in Israel the tendency toward inclusion was already legislated in 1988, and has developed continuously since then. Our findings, which represent a similarity across the range of 6 to 20 years of experience rather than a gradual increase in SE (Figure 3), may be explained by the potential influence of negative experiences when teachers taught classes that included students with disabilities, but during a time when supports, services, and knowledge were still lacking (Fejgin et al., 2005).

\subsubsection{Previous Acquaintance and Experience with Students with Disability}

In the current study, it was found that teachers who have had experience with students with disability had more favorable attitude scores than the other teachers.

Previous studies have revealed equivocal findings, with some of them reporting that experience with students having certain disabilities led to positive attitude formation (e.g., Block \& Rizzo, 1995; Obrusnikova, 2008; Özer et al., 2013; Rizzo \& Vispoel, 1991), and other studies reporting no such effect (Block \& Rizzo, 1995; Rizzo, 1984; Schmidt-Gotz et al., 1994). Most authors who have found supportive evidence for longer acquaintance supported their findings with the Contact Theory (Allport, 1954), which suggests that the amount and type of contact is related to its effect. However, since the reported studies were cross-sectional, it is also likely that those teachers with an a priori more positive attitude toward students with disability would reach out for opportunities to include them in their classes. The message for the pedagogical practice seems to be that when practical sessions are provided within the teacher training curriculum, they should be pedagogically planned and controlled so as to ensure a positive interaction, which will in turn increase SE and ultimately a favorable attitude toward inclusion.

\subsubsection{Participation in Course Work Pertaining to Children with Disabilities}

Similar to previous experience, the PE teachers in our sample who had attended academic courses pertaining to children with disabilities (i.e., APE) had more favorable perceptions of SE regarding the inclusion practice, and their attitudes were more favorable compared to teachers who had not attended such courses. This can be explained by suggesting that participating in academic course work provides the teacher with knowledge and skills that may help him or her to include students with disabilities in the class. For example, Özer et al. (2013) revealed, in a comprehensive study conducted in Turkey, that those teachers who attended course work in APE presented higher SE toward inclusion of students with ID than teachers who did not take part in such courses. However, in a previous study in the USA, APE course participation was not found to be a significant predictor of attitudes (Vaughn, Schuman, Jallad, Slusher, \& Samuel, 1996). Thus, further study is needed to better establish the impact of course work on PE teachers' attitudes and SE toward inclusion. Furthermore, the structure, content, and volume of the course work need to be studied. Ablend of online courses (Healy et al., 2017), adaptation skills, and pedagogically-structured practical sessions is recommended for this purpose. 


\subsection{Association between Attitude and SE Instruments and Subscales}

In the current study the internal relationships between all of the SE-ASPE and ATIPE subscales were large. When observing the associations across instruments, it is apparent that PE teachers who had high SE also demonstrated more favorable attitudes toward including students with a disability in their class; that is, they reported less threat and more opportunities relative to those teachers who had lower SE. The findings obtained in the current study indicate a stronger association across instruments than those reported by Hutzler et al. (2005) with Hebrew-speaking PETE students and a different SE instrument, presenting negative correlations of 0.42 and 0.34 between the ATIPE and the "threat to teacher" and "threat to class" factors observed in the original instrument, respectively. In this regard the practicing Arab-speaking teachers appear to have stronger associations than the Hebrew-speaking PETE students assessed in the previous study. These associations can be explained based on Social-Learning Theory (Bandura 1993; 1997; 2005) as well as the Theory of Planned Behavior (Ajzen, 2005), suggesting that teachers who are in greater perceived control of the situation tend to feel less threatened and envision the opportunities rather the barriers within the inclusion environment.

\subsection{Impact of Disability Type}

The association between disability subscales in the SE-ASPE was significant and large $(r>0.8)$. These associations were stronger than those reported in previous studies, particularly the recent Spanish study of Reina et al. (2016) that reported moderate $r$ scores (between 0.575 - 0.648). This finding indicates that teachers who reported high SE toward one disability also reported high SE scores toward the inclusion of children with different types of disability. Given the impact of course work and experience as reported earlier, it can be suggested that there might be a certain carryover effect from successful inclusion of children with one type of disability to the other types. However, based on our findings a hierarchy of SE toward different disability profiles appears to exist, where VI seems to be associated with the lowest SE compared to PD and ID. Previous studies have reported that in comparison to classroom or music teachers, PE teachers have described less favorable attitudes toward including children with PD, ID, or VI (Downs \& Williams, 1994; Hodge \& Jansma, 1999; Rizzo, 1984; Rizzo \& Vispoel, 1991; Sideridis \& Chandler, 1996). This was the reason that Block et al. (2013) included these disabilities in the SE-ASPE scale. Our study adds an additional gap in teachers' SE toward inclusion across disabilities. Given that such a gap may be confirmed in additional studies, concentrating on disability profiles such as VI and to a lesser extent PD and ID - where teachers indicate the lowest SE toward inclusion during teacher training programs, seems necessary in the future.

\subsection{Limitations}

The current study has several limitations: (a) The instruments used in this study did not control for age of disability. A selection of age attributes was used in order to realistically challenge the PE teachers. Previous research has indicated differences in physical educators' attitudes towards teaching children of different ages and disabilities. Specifically, the age children are being taught appears to matter, reporting better attitudes towards K-3 children than towards children in grades 7-8 (Rizzo, 1984). (b) The sample included in the current study was from a specific geographic area of the Arabic-speaking population in Israel, which is the northern part near Nazareth. It may be possible that PE teachers in other geographical areas would have different outcomes due to different socio-cultural contextual factors.

\section{Summary and Recommendations}

In the current study, a sample of Arabic-speaking PE teachers from the northern part of Israel completed questionnaires, addressing their attitudes and SE toward including children with disability in their class. The previously validated questionnaires were translated into Arabic and confirmed for internal reliability. Furthermore, the inter-scale correlations were moderate to high and corresponded to theoretical expectations. The impact of selected background variables on attitudes and SE in the study population was determined referring to gender, age, teaching experience, APE training, and past acquaintance with children with disabilities. The results indicated more similarities than differences compared to other samples of American, European, or Hebrew-speaking Israeli PE teachers or students. Specifically, the impact of previous course work in APE was indicated as useful. The analysis of SE toward inclusion across disability profiles indicated less favorable scores for VI compared to ID and PD. Based on our findings, it can be recommended to strengthen the knowledge translation [what is "knowledge translation"? Maybe "...to strengthen the transfer of knowledge..?] of adaptation practices during teacher training, and especially to provide continuous education workshops on inclusion, that give particular emphasis on SE-threatening disabilities such as VI. More than two introductory courses seem to be required [are probably required...?] for this purpose. Furthermore, it is recommended that the degree of teacher attitudes and perceived SE toward inclusion across disabilities be studied in the Hebrew-speaking sector in Israel, as well as in other countries, to better prepare for the full participation of childre $n$ with disabilities in PE. 


\section{References}

Ajzen, I. (1991) The theory of planned behavior. Organizational Behavior and Human Decision Processes, 50(2), 179-211. https://doi.org/10.1016/0749-5978(91)90020-T

Ajzen, I. (2005). Attitudes, personality and behavior. New York, NY: Open University Press.

Allport, G. (1954) The nature of prejudice. Reading, MA: Addison-Wesley.

Aloia, G. F., Knutson, R., Minner, S. H., \& Von Seggern, M. (1980). Physical education teachers' initial perceptions of handicapped children. Mental Retardation, 18, 85-87.

Alsalhe, T. A. (2013). Adapted physical education in Middle East countries. Hacettepe Journal of Sport Sciences, 24(2), $105-110$.

Antonak, R., \& Livneh, H. (1988). Studies of attitudes toward the handicapped: the need for a new direction. Social Problems, 28, 321-337.

Bain, L. (1990). Physical education teacher education. In W. R. Houston, M. Haberman, \& J. Sikula (Eds.), Handbook of research on teacher education (pp. 758-781). New York, NY: Macmillan.

Baloun, L., Kudlacek, M., Sklenarikova, J., Jesina, O., \& Migdauova, A. (2016). Czech self-efficacy scale for physical education majors towards children with disabilities. Acta Gymnica, 46(1), 44-54. https://doi.org/10.5507/ag.2016.002

Bandura, A. (1993) Perceived self-efficacy in cognitive development and functioning. Educational Psychologist, 28(2), 117-148. https://doi.org/10.1207/s15326985ep2802_3

Bandura, A. (1997). Self-efficacy: The exercise of control. New York, NY: Freeman.

Bandura, A. (2005). The evolution of social cognitive theory. In K. G. Smith \& M. A. Hitt (Eds.), Great minds in management (p. 1). Oxford, UK: Oxford University Press.

Bandura, A. (2006). Guide for constructing self-efficacy scales. In F. Pajares \& T. Urdan (Eds.), Self-efficacy beliefs of adolescents (Vol. 5, pp. 307-337). Greenwich, CT: Information Age Publishing.

Barton, L. (1993). Disability, empowerment and physical education. In J. Evans (Ed.), Equality, education and physical education (pp. 43-54). London, UK: The Falmer Press.

Block, M. E., \& Rizzo, T. (1995). Attitudes and attributes of physical educators associated with teaching individuals with serve and profound disabilities. The Journal of Persons with Severe Handicaps, 20, 80-87. https://doi.org/10.1177/154079699502000108

Block, M. E., \& Obrusnikova, I. (2007). Inclusion in physical education: A review of the literature from 1995-2005. Adapted Physical Activity Quarterly, 24, 103-124. https://doi.org/10.1123/apaq.24.2.103

Block, M. E., Hutzler, Y., Klavina, A., \& Barak, S. (2013). Creation and validation of the situational-specific self-efficacy scale. Adapted Physical Activity Quarterly, 29, 184-205. https://doi.org/10.1123/apaq.30.2.184

Block, M. E., Taliaferro, A., Harris, N., \& Krause, J. (2010). Using self-efficacy theory to facilitate inclusion in general physical education. Journal of Physical Education, Recreation \& Dance, 81(3), 43-46. https://doi.org/10.1080/07303084.2010.10598448

Brislin, R. (1970). Back-translation for cross-cultural research. Journal of Cross-Cultural Psychiatry, 1, 185-216. https://doi.org/10.1177/135910457000100301

Central Bureau of Statistics (CBS). (2006). Table 2. Local councils and municipalities socio-economic index by ranking and cluster membership http://www.cbs.gov.il/publications/local_authorities06/pdf/t02.pdf

Central Bureau of Statistics (CBS). (2016). Sources of population growth Table 2.12. http://www.cbs.gov.il/shnaton67/st02_12.pdf

Chmaissi, R. (2003). The Nazareth region: A metropolitan framework for management, planning and development. Jerusalem: Floeresheimer Institute for Policy Research [In Hebrew] Online: http://fips.huji.ac.il/sites/default/files/floersheimer/files/khamaisi_the_nazareth_area.pdf

Chubon, R. A. (1982). An analysis of research dealing with attitudes of professionals toward disability. Journal of Rehabilitation, 48(1), 25-30.

Cohen, J. (1988). Statistical power analysis for the behavioral sciences (2nd ed.). Hillsdale, NJ: Lawrence Earlbaum Associates. 
Columna, L., Hoyos-Cuartas, L. A., Foley, J. T., Perez, J. R. P., Chavarro-Bermeo, D. M., Mora, A. L., ... Rivero, I. (2016). Latin American physical educators' intention to teach individuals with disabilities. Adapted Physical Activity Quarterly, 33(3), 213-232. https://doi.org/10.1123/APAQ.2014-0167

Costello, A. B., \& Osborne, J. W. (2005). Best practices in exploratory factor analysis: Four recommendations for getting the most from your analysis. Practical Assessment, Research, \& Evaluation, 10, 1-9.

Dorđić, V., Tubić, T., \& Protić, B. (2014). The attitudes of teachers of rural and urban schools to inclusive physical education. Sportske nauke i zdravlje, 4(1), 33-40.

Doulkeridou, A., Evaggelinou, \& Kudláček, M. (2010). Components of attitudes toward the inclusion of students with disabilities in physical education in the ATIPDPE-GR instrument for Greek physical educators. Acta Universitatis Palackianae Olomucensis, Gymnika, 40(4), 63-68.

Downs, P., \& Williams, T. (1994) Student attitudes toward integration of people with disabilities in activity settings: A European comparison. Adapted Physical Activity Quarterly, 11(1), 32-43. https://doi.org/10.1123/apaq.11.1.32

Fejgin, N., Talmor, R., \& Erlich, I. (2005). Inclusion and burnout in physical education. European Physical Education Review, 11, 29-50. https://doi.org/10.1177/1356336X05049823

Field, A. (2005). Discovering statistics using SPSS (2nd ed.). Thousand Oaks, CA: Sage Publications.

Florian, L., \& Black-Hawkins, K. (2011). Exploring inclusive pedagogy. British Educational Research Journal, 37(5), 813-828. https://doi.org/10.1080/01411926.2010.501096

Florian, V., Weisel, A., Kravetz, S., \& Shurka-Zernitsky, E. (1989). Attitudes in the Kibbutz and city toward persons with disabilities: Amultifactorial comparison. Rehabilitation Counseling Bulletin, 32, 210- 218.

Hasnein, R., Shaikh, L. C., \& Shanawani, H. (2008). Disability and the Muslim perspective: An introduction for rehabilitation and health care providers. Cornell University GLADNET Collection. Available at: http://digitalcommons.ilr.cornell.edu/cgi/viewcontent.cgi?article=1462\&context=gladnetcollect

Healy, S., Judge, J., Strehli, L., Colombo-Dougovito, A., Kwon, E., \& Block, M. (2017). A practical guide to the development of an online course in adapted physical education. Palaestra, 31(20), 48-54.

Hodge, S. R., \& Jansma, P. (1999). Effects of contact time and location of practicum experiences on attitudes of physical education majors. Adapted Physical Activity Quarterly, 16, 48-63. https://doi.org/10.1123/apaq.16.1.48

Hodge, S. R., Davis, R., Woodward, R., \& Sherrill, C. (2002). Comparison of practicum types in changing preservice teachers' attitudes and perceived competence. Adapted Physical Activity Quarterly, 19(2), 155-171. https://doi.org/10.1123/apaq.19.2.155

Hutzler, Y. (2003). Attitudes toward the participation of individuals with disabilities in physical activity: AReview. Quest, 55, 347-373. https://doi.org/10.1080/00336297.2003.10491809

Hutzler, Y., Zach, S., \& Gafni, O. (2005). Physical education students' attitudes and self-efficacy towards the participation of children with special needs in regular classes. European Journal of Special Needs Education, 20(3), 309-327. https://doi.org/10.1080/08856250500156038

Kudláček, M., Blanková, B., \& Filipčič, T. (2007). Indicators of attitudes toward inclusion of students with physical disabilities in PE in the "ATIPDPE-SL"instrument for prospective Slovene physical educators and general educators. Kinesiologia Slovenica, 13(2), 43-51.

Kudlaček, M., Valkova, H., Sherrill, C., Myers, B., \& French, R. (2002). An inclusion instrument based on planned behavior theory for prospective Czech physical educators. Adapted Physical Activity Quarterly, 19, 280-299. https://doi.org/10.1123/apaq.19.3.280

Lieberman, L. J., Robinson, B., \& Rollheiser, H. (2006). Youth with visual impairments: Experiences within general physical education. RE: View, 38(1), 35-48. https://doi.org/10.3200/REVU.38.1.35-48

Lienert, C., Sherrill, C., \& Myers, B. (2001). Physical educators' concerns about integrating children with disabilities: A cross-cultural comparison. Adapted Physical Activity Quarterly, 18, 1-17. https://doi.org/10.1123/apaq.18.1.1

Meegean, S., \& MacPhail, A. (2006). Irish physical educators attitude toward teaching students with special educational needs. European Physical Education Review, 12 (1), 75-97. https://doi.org/10.1177/1356336X06060213

Obrusnikova, I. (2008). Physical educators' beliefs about teaching children with disabilities. Perceptual and Motor Skills, 106(2), 637-644. https://doi.org/10.2466/pms.106.2.637-644

Özer, D., Nablant, S., Ağlamis, E., Baran, F., Kaya Samut, P., Aktop, A., \& Hutzler, Y. (2013). Physical education 
teachers' attitudes towards children with intellectual disability: the impact of time in service, gender, and previous acquaintance. Journal of Intellectual Disability Research, 57(11), 1001-1013. https://doi.org/10.1111/j.1365-2788.2012.01596.x

Patrick, G. D. (1987). Improving attitudes toward disabled persons. Adapted Physical Activity Quarterly, 4, 316-325. https://doi.org/10.1123/apaq.4.4.316

Pedersen, S. J., Cooley, P. D., \& Hernandez, K. (2014), Are Australian pre-service physical education teachers prepared to teach inclusive physical education? Australian Journal of Teacher Education, 39(8), 53-62. https://doi.org/10.14221/ajte.2014v39n8.4

Peters, S. J. (2009). Inequalities in education for people with disabilities. In D. B. Holsinger \& W. J. Jacob (Eds.), Inequality in education (pp. 149-171). Netherlands: Springer.

Polloway, E. A., Smith, J. D., Patton, J. R., \& Smith, T. E. C. (1996). Historical changes in mental retardation and development disabilities. Education and Training in Mental Retardation and Development Disabilities, 31, 3-12.

Qi, J, Wang, L., \& Ha, L. S. C. (2016) Perceptions of Hong Kong physical education teachers on the inclusion of students with disabilities. Asia Pacific Journal of Education.

Reina, R., Hemmelmayer, I., \& Sierra-Marroquín, B. (2016). Autoeficacia de profesores de educación física para la inclusión de alumnos con discapacidad y su relación con la formación y el contacto previo [In Spanish] [Self-efficacy of physical education teachers toward inclusion of students with disabilities and regarding their previous training and experiences]. Psychology, Society, \& Education, 8(2), 93-103. https://doi.org/10.25115/psye.v8i2.455

Rizzo, T. L. (1984). Attitudes of physical educators toward teaching handicapped pupils. Adapted Physical Activity Quarterly, 1(3), 267-274. https://doi.org/10.1123/apaq.1.4.267

Rizzo, T. L., \& Vispoel, W. P. (1991). Physical educators' attributes and attitudes toward teaching students with handicaps. Adapted Physical Activity Quarterly, 8, 4-11. https://doi.org/10.1123/apaq.8.1.4

Rizzo, T. L., \& Wright, R. G. (1988). Selected attributes related to physical educators' attitudes toward teaching students with handicaps. Mental Retardation, 26, 307-309.

Rowe, J., \& Stutts. R. (1987). Effects of practica type, experience, and gender on attitudes of undergraduate physical education majors toward disabled persons. Adapted Physical Activity Quarterly, 4(4), 268-277. https://doi.org/10.1123/apaq.4.4.268

Schmidt-Gotz, E., Doll-Tepper, G., \& Lienert, C. (1994). Attitudes of university students and teachers towards integrating students with disabilities in regular physical education classes. Physical Education Review, 17, 45-57.

Shahi, Z., \& Jadidi, B. (2013). Situation of adapted physical activity for persons with disability in Iran. Hacettepe Journal of Sport Sciences, 24(2), 119-122.

Shechtman, Z. (1991) Changing attitudes of teachers in regular education toward integrating the exceptional in regular settings: empirical findings and an intervention plan. Dapim, 13, 54-59 [in Hebrew].

Sideridis, G. D., \& Chandler, J. P. (1996). Comparison of attitudes of teachers of physical and musical education toward inclusion of children with disabilities. Psychological Reports, 78(3), 768-770. https://doi.org/10.2466/pr0.1996.78.3.768

Tabachnick, B. G., \& Fidell, L. S. (2001). Using multivariate statistics (4th ed.). Needham Heights, MA: Allyn \& Bacon.

Taliaferro, A. R., Hammond, L., \& Wyant, K. (2015). Preservice physical educators' self-efficacy beliefs toward inclusion: The impact of coursework and practicum. Adapted Physical Activity Quarterly, 32, 49-67. https://doi.org/10.1123/apaq.2013-0112

Triandis H. C. (1971) Attitude and attitude change. New York, NY: J. Wiley \& Sons.

Tripp, A., \& Rizzo, T. (2006). Disability labels affect physical educators. Adapted Physical Activity Quarterly, 23, 310-326. https://doi.org/10.1123/apaq.23.3.310

United Nations. (2006). Convention on the rights of persons with disabilities. New York: NY, United Nations. ISBN $9780101790529, \mathrm{Cm} 7905$.

Vaughn, S., Schuman, J., Jallad, B., Slusher, J., \& Samuel, L. (1996). Teachers' views of inclusion. Learning Disabilities Research and Practice, $11(2), 96-106$.

Velicer, W. F., \& Fava, J. L. (1998). Effects of variable and subject sampling on factor pattern recovery. Psychological 
Methods, 3, 231-251. https://doi.org/10.1037/1082-989X.3.2.231

Wood, R. E., \& Bandura, A. (1989) Social cognitive theory of organizational management. Academy of Management Review, 14(3), 361-384.

Worgen, Y. (2007). The operationalization of the Integration Law. The report was submitted to the Knesset Committee on Education, Culture and Sport. (in Hebrew). Available at https://www.knesset.gov.il/mmm/data/pdf/m01813.pdf

\section{Copyrights}

Copyright for this article is retained by the author(s), with first publication rights granted to the journal.

This is an open-access article distributed under the terms and conditions of the Creative Commons Attribution license which permits unrestricted use, distribution, and reproduction in any medium, provided the original work is properly cited. 